\section{(6) OPEN ACCESS}

${ }^{1}$ Emergency Department, St Mary's Hospital, Imperial College Healthcare NHS Trust, London, UK

${ }^{2}$ Centre for Patient Safety and Service Quality, Department of Surgery and Cancer, Imperial College, London, UK

\section{Correspondence to}

Dr Maisse Farhan, Emergency Department, First Floor OEQM St Mary's Hospital, Praed Street, London W2 1NY, UK; maisse.farhan@imperial.nhs.uk

Accepted 20 November 2011

Published Online First 3 January 2012

\title{
The $A B C$ of handover: a qualitative study to develop a new tool for handover in the emergency department
}

\author{
Maisse Farhan, ${ }^{1}$ Ruth Brown, ${ }^{1}$ Maria Woloshynowych, ${ }^{2}$ Charles Vincent ${ }^{2}$
}

\begin{abstract}
Objectives This study identifies best practice for shift handover and introduces a new tool used to hand over clinical and operational issues at the end of a shift in the emergency department (ED).
\end{abstract}

Methods Literature review, semi-structured interviews and observations of handover were used to develop a standardised process for handover. Participants were ED middle grades, consultants and senior nurses. Interviews were used to identify agreed best practice and derive a tool to classify the information into relevant sections.

Results Interviews identified a variety of perceived current deficits in handover including a lack of standardised practice and structure. Participants provided examples of poor handover that were thought to have led to adverse events; these included delay in investigations and treatment for patients who were handed over with brief or inaccurate information. There was wide variation in the understanding of the meaning and purpose of shift handover, and differences were apparent according to the level of experience of the middle grades interviewed. The experts' responses were used to reach a unifying 'best practice' for the content of handover. This was then grouped under $A B C D E$ headings to develop the $\mathrm{ABC}$ of handover tool.

Conclusions A simple tool was developed to provide the basis for medical shift handover, which includes clinical and operational information necessary for efficiency and organisation of the next shift. The ABC of handover classifies shift information to be handed over under the $A B C D E$ headings, which are easy to remember and highly relevant to emergency medicine.

Accurate communication of information at the end of the shift is one of the primary functions of handover to ensure safe transition of shift responsibility from the outgoing to the incoming teams in a healthcare setting. ${ }^{1-3}$ Despite this, formal training and standardisation of the structure of handover is not widely available in healthcare, ${ }^{4}$ and handover has been reported in a survey of UK doctors to be frequently of poor quality. ${ }^{5}$ Since the implementation of 'Modernising medical careers' 6 in the UK, the total duration of training has been reduced, and in combination with the requirements of the European working time directive (EWTD) it is inevitable that doctors have less experience as a result of shorter hours and shorter duration of training. Handover is a skill, that is not formally included in medical training, and doctors should receive dedicated training in the importance and best practice for handover. International researchers have identified a gap in the evidence and practice of handover and called for interventions to standardise it. ${ }^{\text {? }}$
Handover can involve the transfer of information concerning a single patient (such as when a doctor or nurse reaches the end of their shift), or it can involve the transfer of responsibility of a whole department, ie, the transfer of overall responsibility of a department with all its patients and staff as well as other issues to the oncoming doctors. This responsibility traditionally lies with the senior doctor and nurse in charge of the shift. Effective shift handover is complex but vital for the smooth, efficient and safe transition between shifts in the emergency department (ED). In this paper we describe the $\mathrm{ABC}$ of handover; a new method for end-of-shift handover for doctors in charge of ED, and illustrate the implementation and uses of this method. A companion paper describes the formal evaluation of the $\mathrm{ABC}$ of handover.

The EWTD mandates that junior doctors work shorter shifts necessitating more frequent handovers. In the UK it is recommended that a senior doctor (middle grade level or above) is available $24 \mathrm{~h}$ a day to provide clinical decision making for all patients attending the ED. ${ }^{8}$ This senior doctor is unlikely to be able to review all patients that attend the ED, but would be aware of high-risk patients, any challenges or potential issues. This senior doctor would have overall knowledge of the patients in the department as well as awareness of processes involved in facilitating investigations necessary for treatment, admission or discharge in a timely fashion compliant with the $4 \mathrm{~h}$ access standard as set by the UK Department of Health. ${ }^{9}$ They would ensure efficient throughput of patients, have the overall responsibility for the management of patients clinically, and provide solutions for problems arising on the shift that may pose a risk to patients as well act in an advisory role for doctors in training. Handover at the end of the shift involves conveying various aspects of the shift, including outstanding actions to ensure the transition of responsibility is a safe process. This study concerns the process with which senior doctors hand over the overall responsibility of the whole department at the end of the shift. This is complex and vital for the smooth and efficient operation of the next shift. Hence the need to standardise in order to ensure safe transition.

\section{LITERATURE REVIEW}

The purpose of clinical handover has been previously studied and shown to include the transfer of patient information as well as team building, teaching and group cohesion. ${ }^{10}$ Several studies have shown that handover is a vulnerable time for patient safety, providing further reasons for healthcare professionals to invest in training for handover. 
One study showed that poor handover was one of the most prevalent causes leading to medical error as a result of team work problems. A survey of doctors' practice and perceptions reported that up to $15 \%$ of critical incidents arose from poor handover. International researchers in clinical safety have highlighted a growing interest in improving handover, yet there are only a relatively small number of high quality evidence-based interventions that are applicable to the ED. The National Patient Safety Agency published recommendations for assessing highrisk areas such as handover in the hospital at night and in collaboration with the British Medical Association provided a guide to safe handover. Recommendations include a dedicated time for shift handover, with clear leadership that includes concerns from the previous shift as well as outstanding tasks. However, this mainly applies to ward-based handover of inpatients.

Attempts have been made to improve and standardise end-ofshift handover and include using standardised operating protocols $^{11} 12$ and IT interventions. ${ }^{13} 14$ A computerised handover system was shown to reduce adverse events relating to inpatients. ${ }^{15}$ However, implementing such systems in the ED may require further time dedicated for training and frequent use and may be impractical. Verbal mnemonic aids have been developed for junior medical doctors to be used for ward handover such as 'JUMP'16 (Jobs outstanding, Unseen patients, Medical contacts, Patients to be aware of) and 'ANTICipate'17 (Administrative data, New information, Tasks, Illness, Contingency planning). Our study develops a mnemonic relevant to emergency medicine with familiar headings that provide clear guidance to the items required for handover.

\section{SETTING FOR DEVELOPIENT OF THE ABC OF HANDOVER}

St Mary's adult ED is based at an inner city London teaching hospital, with an annual rate of new attendances of 80000 patients and a total hospital capacity of 350 acute beds. There is a separate paediatric ED within the department. This study is based in the adult ED, which has a capacity for 26 patients in cubicles, and two waiting areas (one for minor illnesses/injuries and one for patients with major illnesses). There is a twelve bedded clinical decisions unit (CDU). The department is geographically sectioned into areas that house patients of different acuity: the resuscitation room is set up for critically ill or injured patients; the 'majors' area is for those with similar conditions but requiring less intensive observations; and the 'minors' area is for those with illnesses or injuries likely to be of a faster turnover. The CDU is for those requiring a prolonged period of observation or requiring additional investigations.

There are five consultants who lead three daily ward rounds in the adult department at 08:00, 12:00 and 16:00 hours. An additional ward round is led by the middle grade at 22:00 hours. Middle grades provide $24 \mathrm{~h}$ cover of whom one per shift is assigned the overall responsibility of the department. The department is staffed by a full nursing complement.

The rota is compliant with the EWTD and takes into account recommendations by the Royal College of Physicians on handover, ${ }^{18}$ with an overlapping hour dedicated for handover at shift change-over times. ED doctors hand over under the supervision of a consultant during working hours and in the presence of the incoming and outgoing middle grades, as well as the nurse in charge and junior doctors. The consultant leads the ward rounds and frequently delivers teaching and directs the clinical management of patients discussed, and supervises handover between middle grades. This practice is reproduced by middle grades out of hours and at weekends.
In common with all ED patient volume is high. In our department the number can be in excess of 250 per day, and performance standards in the UK mandate throughput of patients within $4 \mathrm{~h}$. ED patients are often complex and deterioration cannot always be anticipated. Furthermore, ED patients are frequently reviewed by inpatient teams creating a heavier load of information to be passed between healthcare professionals. The shift leader is required to have knowledge of all patients in the department in order to prioritise them and organise investigations necessary to make decisions. This adds to the importance of having a robust system with which safe hand over of responsibility can occur.

\section{PHASES OF DEVELOPING THE ABC OF HANDOVER}

The new handover process was devised using qualitative methods: encompassing reflections and observations of current practice, and interviews with ED staff. Reference to the literature was also used in developing the handover tool. There were some principles from non-healthcare based research as well as clinical research surrounding the best practice for safe handover structures, which contributed to the development of this method of handover.

\section{Phase 1: preliminary observations of current practice}

Handovers were observed by the researcher (MF) to note the content and structure of current practice. The routine practice at the time of handover and board/ward rounds in our department before this study involved an overview of the patients in the resuscitation area, 'majors' and CDU, where for the majority, the case is briefly discussed and decisions are made accordingly. For some patients further review took place after handover. CDU patients were usually reviewed several times a day either by the consultant or the middle grade in charge of the shift. There was no structure or routine format for handing over operational or organisational issues. Middle grades did not routinely hand over operational issues that arose during the shift, which made it difficult for the incoming shift to anticipate and deal with problems that arose. Overall, there was a culture and practice of reacting to problems as they arose, rather than proactive management and anticipation. It was clear that a system of handover was required in which problems were anticipated allowing for better preparation and enabling middle grades to develop the skill of a wider situational awareness of the overall state of the department.

\section{Phase 2: interviews}

Semistructured interviews were carried out with 15 ED staff to examine their views on current practice, the purpose of handover, problems with handover and how it might be improved. All six ED consultants (adult and paediatric) were interviewed to provide expert opinions, middle grade doctors were interviewed to provide an opinion from those who carry out daily handover. The senior nurse and nurse consultant were interviewed to provide additional expert opinions. Interviews with middle grade doctors were stopped after seven doctors revealed no new information.

The purpose of the interviews was twofold: to obtain a consensus from experts in emergency medicine on best practice and to reveal perceptions on handover and any problems encountered. The interviews were recorded and transcribed Information extracted from the interviews was analysed using 'grounded theory', ${ }^{19}$ in which themes were identified and categorised as they emerged from the data. 
A consensus for 'best practice' for shift handover was derived from the interviews with consultants and senior nurses in emergency medicine and a mnemonic was devised that contained all items included in the agreed 'best practice'.

\section{Interview findings}

\section{Definition, purpose and content of handover}

Interviews with middle grades revealed a wide variation in the understanding of shift handover. Junior middle grades described shift handover to be the transfer of information concerning an individual patient with outstanding tasks, its purpose being a 'run-through' of tasks outstanding for individual patients. Experienced middle grades explained the concept of shift handover to be the transfer of clinical as well as operational information such as staffing, bed issues and patients approaching 4-h breach times. They also stated that the purpose of shift handover was minimising errors and ensuring safety, and knowledge of problems that may affect the next shift. All middle grades declared that a good handover was a requirement for the safe operation of the subsequent shift.

There was agreement among the consultants and senior nurses on the definition of handover to be a transfer of information between shifts to ensure safety, efficiency and continuity of care. In addition, it would serve to identify potentially unwell patients, actions outstanding and an opportunity for decision making on a large number of patients in a short time. They stated that handover should ideally serve as a platform for foresight and anticipation of problems (clinical and operational) and a discussion around possible solutions. In the experts' opinion handover was to include clinical information, staffing issues, operational events, equipment overview and strategies to organise and prepare for the next shift. In addition, it was used as an opportunity for education and a chance to establish working patterns during special circumstances (such as local sporting events)

\section{Who, when, where?}

All participants stated that handover should include consultants, the middle grade in charge, junior doctors, nurse in charge,

\section{Box 1 'Best practice' and the ABC of handover}

The majority of participants deemed the following items to be necessary for a good handover:

1. Written record of handover in a standardised format

2. Discussion of patients including those under the care of speciality teams

3. Equipment problems

4. 4 hour standard performance

5. Bed issues

6. Waiting times

7. Deaths occurring in the department

8. Violence/aggression

9. Staff sickness

10. Agency staff presence

admissions ward physician, occupational therapists and elderly falls service. There was also agreement that handover should occur with the current times that the lead middle grade hands over responsibility (08:00, 16:00, 22:00 hours). It was also suggested that a brief review of progress half way through the shifts (24:00 and 18:00 hours) should occur. Participants stated that handover should occur in a dedicated area that ensures privacy and confidentiality, and has access to IT systems.

\section{Poor handover: examples, perceived reasons, consequences}

Interviewees reported that patients frequently experienced delays and inadequate care due to poor shift handover, sometimes with serious consequences. The frequency of receiving a poor handover ranged from 'everyday' to 'once a fortnight'. The majority estimated they had wasted $1-3 \mathrm{~h}$ per shift catching up with issues following a poor handover. One middle grade stated they had spent a whole shift $(10 \mathrm{~h})$ catching up after they had received poor or no handover. Numerous hours were thus wasted highlighting inefficient practice and a need to

Table 1 Details of items on the $A B C$ of handover

\begin{tabular}{|c|c|c|}
\hline & Content & Purpose \\
\hline \multicolumn{3}{|l|}{ A } \\
\hline Areas and Allocation & Patient numbers, waiting times, doctor allocation to each area & Redistribute staff to areas in need \\
\hline \multicolumn{3}{|l|}{$B$} \\
\hline Beds & Bed situation & Plan admissions in advance \\
\hline Bugs & Infection control issues (patients needing isolation, outbreaks or bay closures) & $\begin{array}{l}\text { Plan side rooms, prompt isolation, arrange deep clean, } \\
\text { highlight bed closures }\end{array}$ \\
\hline Breaches & Patients approaching the 4-h trolley wait (including recent 'breaches') & Early referral decisions and avoid further delays \\
\hline \multicolumn{3}{|l|}{ C } \\
\hline Colleagues & $\begin{array}{l}\text { Staffing issues in ED and speciality teams, radiology waits, support by } \\
\text { porters and laboratories }\end{array}$ & $\begin{array}{l}\text { Anticipate problems on the next shift, prompt arranging } \\
\text { cover from agencies }\end{array}$ \\
\hline Consultant on Call & Consultant on call to be named for every shift & Clarity if contact is required \\
\hline \multicolumn{3}{|l|}{$\mathrm{D}$} \\
\hline Deaths & Patients who died, expected relatives, reporting to coroner & $\begin{array}{l}\text { Facilitate procedures, expect relatives, consider distress } \\
\text { among staff }\end{array}$ \\
\hline Disasters & Clinical incidents/events requiring additional security & Prevent further disruption \\
\hline Deserters & Patient who leave before completion of treatment (recognised to be at risk) & Recall and expedite treatment on return \\
\hline \multicolumn{3}{|l|}{$\mathrm{E}$} \\
\hline Equipment & $\begin{array}{l}\text { Equipment failure such as arterial blood gas analysers, computer systems or } \\
\text { 'shute' (transportation of pathology samples) or any other equipment }\end{array}$ & Report faults and make alternative arrangements \\
\hline External Events & Sporting events, local carnivals, hospital events (eg, audit/teaching) & $\begin{array}{l}\text { Expect multiple patients with specific problems, arrange } \\
\text { extra training and resources }\end{array}$ \\
\hline
\end{tabular}


CPSSQ

Imperial College Healthcare W/HS

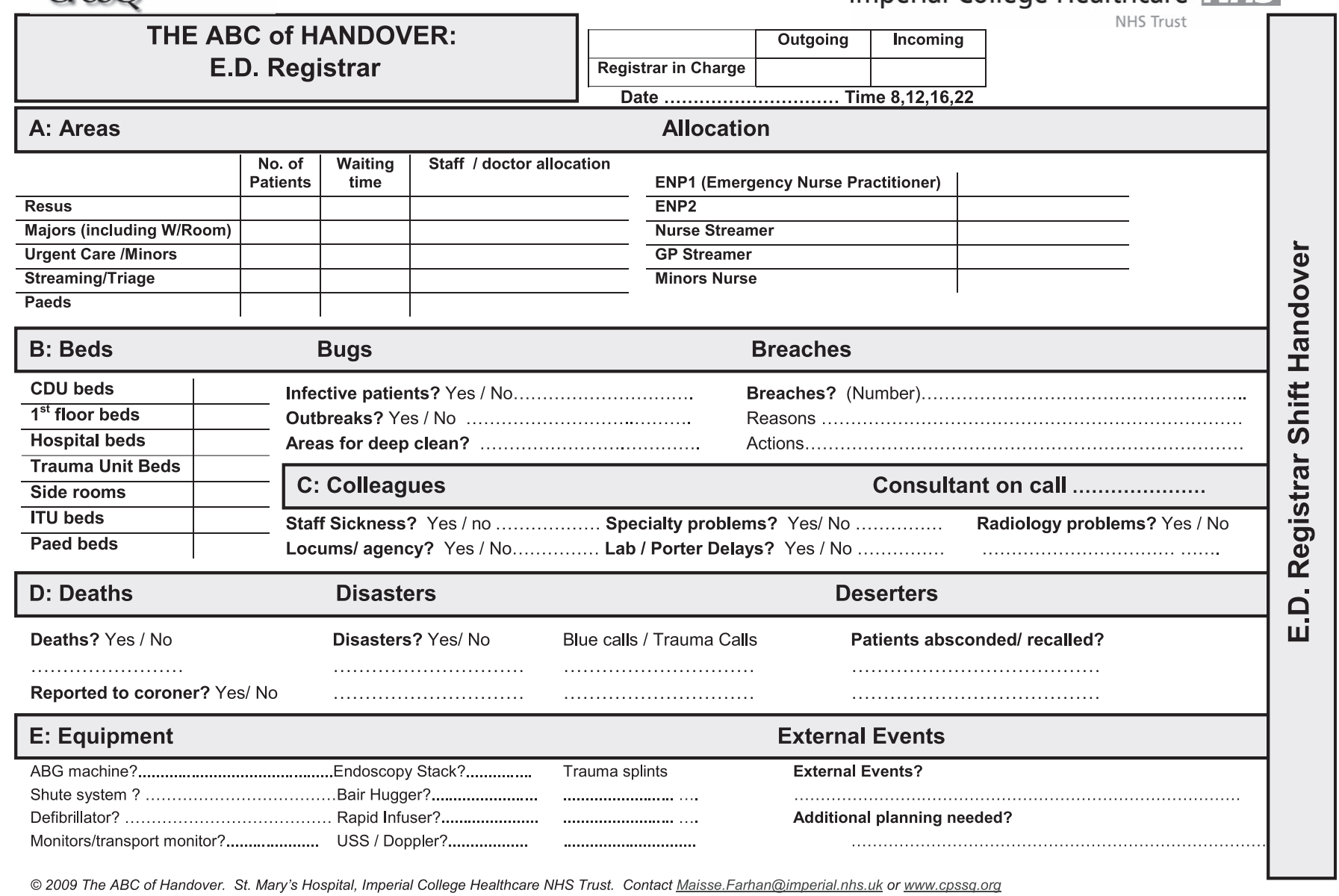

Figure 1 The $A B C$ of handover.

standardise handover. Participants believed the reasons for such handovers were: poor presentation skills, lack of clarity of thought, lack of a clear diagnosis, poor personal skill, shift intensity, variable skill of other staff on the shift, poor preparation for handover, and poor knowledge of the patients. Participants summarised the consequences experienced as prolonged ward round causing delays and time wasting.

\section{Participants' views on improving handover}

The majority of participants suggested either formalising the handover process or providing a written framework in order to standardise the information regardless of the person giving it. One middle grade expressed the need for training and appraisal of the handover process. Standardising handover by using a simple tool that includes clinical and organisational aspects of

\section{Box 2 Top tips for implementing the ABC of handover}

\section{The following steps illustrate a suggested way to implement the ABC of handover}

1. Handover every time shift responsibility changes hands.

2. Senior supervision for handover whenever possible (to provide training and suggest improvement in management decisions).

3. Dedicate a room for handover to ensure confidentiality.

4. Enable the room with IT systems allowing access to patient records and investigations.

5. Ensure as few interruptions as possible to ensure accurate transfer of information.

6. Design rotas to have an overlapping hour for handover.

7. Provide dedicated training on the principles of good handover, ensuring ethos of pro-active not reactive problem solving.

8. Training on the use of the $A B C$ of handover; providing a platform for communication and an overview to organise the team, in order to maximise safety continuity of care.

9. Provide visual aids to the $A B C$ of handover (laminated cards/posters).

10. Provide a written record of the $A B C$ of handover. This can be modified to suit varying set-ups in departments.

11. Scan the ABC of handover into dedicated software for future reference and dispose paper into confidential waste. This ensures confidentiality and provides a historic record events on shift than can be an invaluable source of information.

12. Use handover as an opportunity to train junior doctors both in clinical and managerial skills. 
the shift would address this and allow middle grades to present the information with an overview of the department regardless of their skill or experience. This is the focus and exact aim of the $\mathrm{ABC}$ of handover.

\section{Phase 3: developing the $\mathrm{ABC}$ of handover}

A unifying 'best practice' for the content handover (box 1) was reached under the principle that items handed over were those essential for the safe operation of the next shift. These items were initially classified into clinical (relating to patients and clinical events on the shift), organisational (relating to staffing and efficiency) and operational (relating to admission pathways and facilities)

The $\mathrm{ABC}$ of handover (comprising the $\mathrm{ABCDE}$ mnemonic) was devised to summarise the above areas into categories under headings relevant to emergency medicine. Additional items that were included in the list but less frequently mentioned were also added, such as 'allocation' (of staff in the department), 'bugs' (in reference to infectious outbreaks), 'consultant on call', 'disasters' and 'external events'.
The $\mathrm{ABC}$ of handover takes the following format (and is explained in table 1).

- Areas and Allocation.

- Beds, Bugs and Breaches.

- Colleagues and Consultant on call.

- Deaths and Disasters, including Deserters.

- Equipment and External Events.

Then handover every patient.

The $\mathrm{ABC}$ of handover has been implemented in our department and takes less than 5 min to complete. The information transferred is clearly relevant and invaluable to the operation of the next shift. A written record of these headings on a specifically designed handover sheet is provided to facilitate every shift handover. Written support to handover is a recommendation adapted from research in the field of space shuttle handover. ${ }^{20}$ Figure 1 and box 2 summarise the essential features of handover, provide an example of a typical shift handover and some recommendations for effective handover. Figure 1 is the full $A B C$ of handover written structure (which is also available for download from our website http://www.cpssq.org).

\section{Box 3 An illustration of shift handover with the ABC method}

\section{Areas and allocation}

- Four patients in the resus room all have been seen. It is now our priority to move the stable patients to majors in order to be ready to receive any priority calls. If we can identify patients on the ward round that can move to CDU or be discharged it would be a great help.

- There are eight waiting in majors with a $1 \mathrm{~h}$ wait, I have briefly reviewed them and requested primary investigations, and none are unstable.

- The following doctors are in majors (names them).

- There are 20 patients in minors, waiting time of $1 \mathrm{~h}$.

- There are two doctors and one emergency nurse practitioner in minors.

- The next doctor starting their shift will start in minors.

\section{Beds, bugs and breaches}

- The hospital has five beds and two side rooms, with three empty beds on CDU.

- There are two potentially infective patients in ED (suspected tuberculosis), we have started respiratory precautions. There is one bay closed on care of elderly ward due to diarrhoea.

- There have been three breaches on the shift, one was due to the lack of beds and two were unstable patients in resus. These patients have now been treated and one will need to be admitted to ITU, critical care team are with the patient.

- There are no issues with breaches that could have been avoided.

\section{Colleagues and consultant on call}

- There is one doctor off sick tonight and we are one nurse short in the afternoon. I have requested a locum but failing that the late shift doctor has been contacted and agrees to cover the night if required.

- There will be no agency cover for the nurse so we need to re-shuffle the nursing allocation to ensure all areas are covered.

- The consultant on call tonight is (names them).

Deaths, disasters, deserters

- One person died (details) and needs to be referred to the coroner. This was an out-of-hospital cardiac arrest, the family are on their way to the hospital, can we allocate one registrar and the nurse involved to meet them on arrival?

- There was an incident involving aggression, in which person $\mathrm{X}$ was involved and has needed time away from the department.

- One patient absconded, he was deemed to be vulnerable and we have arranged a welfare visit by the police, if he returns can we make sure he is seen promptly to avoid self-discharge again, and arrange for a psychiatric review.

\section{Equipment and external events}

- The blood gas analyser has run out of paper, we have ordered a replacement and it will arrive at 10:00 hours. In the mean time I have organised with the porters to take samples to ITU (ITU are aware).

- And finally, today is the London marathon, we have a supply of ice in the procedures room freezer, the blood gas analyser should have been fixed by the time patients start to arrive. All fluids are available in resus and rectal thermometer probes are in the top drawer of every resus trolley.

- To refresh everyone's memory, I will go through clinical treatments of heat-related collapse at the end of handover.

Moving on, I will now run through the clinical handover of the patients in the department. 


\section{DISCUSSION}

We have used a mixed methods qualitative research design to develop a handover tool. Handing over essential information in an $\mathrm{ED}$ at the end of the shift is a complex yet important skill that relies on multiple factors. The ED has a fast turnover of patients of variable complexity who are assessed by doctors of variable skill and knowledge. Additional environmental factors that may affect staff performance and patient flow (such as incidents occurring on the shift or capacity problems) also need to be communicated in order to anticipate difficulties during the next shift. Healthcare staff need to be able to recognise potential safety risks and intervene to prevent the occurrence of an incident. There is little training time dedicated to teach healthcare professionals the importance of handover and its implications on patient safety. The National Patient Safety Agency recently published guidelines for medical handover with recommendations such as dedicated bleep free time and the use of IT solutions, which although applicable do not address specific variables relevant to the ED.

This study has a few limitations. Observations may have resulted in the Hawthorne effect, as participants were aware that a study on handover was being conducted. However, any observed behaviour change was likely to be a positive one; ie, issues that might not have normally been handed over were in fact mentioned during the observations. This study aimed to identify best handover practice and therefore any positive behaviour change was beneficial. During the interviews there was a potential bias for participants to reply in a socially desirable way rather than giving their true opinions. In order to overcome this we used open questions and sought to explore true opinions using alternative questions, as well as triangulating the results with observation data.

The $A B C$ of handover aims to enhance the efficiency of handover, reduce unsafe events, improve communication and facilitate senior input and teaching for clinical and operational issues. We identified the items deemed necessary for effective shift handover, and collated the results to create a new structure using a mnemonic relevant to emergency medicine. A simple mnemonic using ABCDE providing a short, relevant and comprehensive method was developed, which classifies shift information under those headings. This structure ensures the transition of relevant information to the next shift leader. The $\mathrm{ABC}$ tool supports training for middle grade doctors on the aspects of shift handover and how to use the information gained to maximise efficiency and safety of the next shift.

$\mathrm{ED}$ in other countries generally have a similar structure. Therefore the $\mathrm{ABC}$ of handover can be applied at shift handover to other departments. A suggested method for implementing and using the $\mathrm{ABC}$ of handover is also provided in box 2 , with an example handover shown in box 3 .

This handover tool is also being adapted for nursing handover and that of other specialities at the end of a shift. A study reported in our companion paper reports the evaluation of the $\mathrm{ABC}$ of bandover, but we recognise that further studies in other departments will be necessary to validate this approach in other settings.

Acknowledgements The authors would like to thank the emergency department at St Mary's Hospital for facilitating this research, and extend special thanks to Dr E Redfern and Dr G Haithornthwaite for their assistance in the ABC of handover, and to Professor R Wears (University of Florida) for his support and expertise.

Funding Funding was provided by the London Deanery for MF to conduct research in clinical safety and in collaboration with the Clinical Safety Research Unit. The Clinica Safety Research Unit is affiliated with the Centre for Patient Safety and Service Quality at Imperial College London, which is funded by the National Institute of Health Research http://www.cpssq.org/index.htm.

\section{Competing interests None.}

Contributors All authors contributed to the design of the study. MF collected and analysed the data. RB and MW reviewed the data analysis. MF wrote the manuscript. All authors contributed to its revision.

Provenance and peer review Not commissioned; externally peer reviewed.

\section{REFERENCES}

1. Singh H, Thomas EJ, Peterson LA, et al. Medical errors involving trainees: a study of closed malpractice claims for 5 insurers. Arch Intern Med 2007;167:2030-6.

2. Jagsi R, Kitch BT, Weinstein DF, et al. Residents report on adverse events and their causes. Arch Intern Med 2005;165:2607-13.

3. Sabir N, Yentis SM, Holdcroft A. A national survey of obstetric anaesthetic handovers. Anaesthesia 2006:64:376-80.

4. Horowitz LI, Krumholz HM, Green ML, et al. Transfers of patient care between house staff on internal medicine wards: a national survey. Arch Intern Med 2006;166:1173-7.

5. Roughton VJ, Severs MP. The junior doctor handover: current practices and future expectations. J R Coll Physicians Lond 1996;30:213-14.

6. Department of Health. Modernising Medical Careers. 2004. http://www.mmc.nhs. uk (accessed Jul 2009).

7. Wong MC, Yee KC, Turner P. Clinical Handover Literature Review. Australia: eHealth Services research group, University of Tasmania, 2008. http://www.safetyandquality. org/ (accessed Jul 2009).

8. The Way Ahead 2008-2012: Strategy and Guidance for Emergency Medicine in the United Kingdom and the Republic of Ireland. London: The College of Emergency Medicine, 2008.

9. Reforming Emergency Care. London: Department of Health, 2001.

10. Lally S. An investigation into the functions of nurses' communication at the inter-shift handover. J Nurs Manag 1999:7:29-36.

11. Alvarado $\mathbf{K}$, Lee $\mathrm{R}$, Christoffersen $\mathrm{E}$, et al. Transfer of accountability: transforming shift handover to enhance patient safety. Healthc 0 2006;9:75-9.

12. Bourne C. Intershift report: a standard for handovers. NT Research 2000;5:451-60.

13. Chacko V, Varvarelis N, Kemp DG. eHand-offs: an IBM(R) Lotus(R) Domino(R) Application for ensuring patient Safety and enhancing resident Supervision in handoff Communications. AMIA Annual Symposium Proceedings 2006:874.

14. McGee-Lennon MR, Carberry M, Gray PD. HECTOR: a PDA Based Clinical Handover System. DCS Technical Report Series. Glasgow, UK: Department of Computing Science, University of Glasgow, UK, 2007:1-14.

15. Petersen LA, Orav EJ, Teich JM, et al. Using a computerized signout program to improve continuity of inpatient care and prevent adverse events. Jt Comm J Qual Improv 1998:24:77-87.

16. McCann L, McHardy K, Child S. Passing the buck: clinical handovers at a tertiary hospital. N Z Med J 2007;120:U2778.

17. Vidyarthi AR, Arora V, Schnipper JL, et al. Managing discontinuity in academic medical centers: strategies for a safe and effective resident sign-out. J Hosp Med 2006;1:257-66.

18. BMA Junior doctors Committee, NHS Modernisation Agency, National Patient Safety Agency. Safe handover: safe patients. Guidance on Clinical Handover for Clinicians and Managers. 2005. http://www.bma.org.uk/images/ safehandover tcm41-20983.pdf (accessed Dec 2011).

19. Pope C, Ziebland S, Mays N. Analyzing qualitative data. BMJ 2000;320:114-16.

20. Patterson E, Roth E, Woods D, et al. Handoff strategies in settings with high consequences for failure: lessons for health care operations Int $J$ Qual Health Care 2004;16:125-32. 